\title{
A rare and successfully managed case of idiopathic thrombocytopenic purpura (ITP) with previous caesarean with splenectomy with hepatitis $\mathrm{C}$ positive
}

\author{
Rajshree Dayanand Katke*
}

\begin{abstract}
Department of Obstetrics \& Gynaecology, Cama and Albless Hospitals, Sir J.J. Group of Hospitals, Mumbai-400001,
\end{abstract} Maharashtra, India

Received: 30 August 2014

Accepted: 19 September 2014

\section{*Correspondence:}

Dr. Rajshree Dayanand Katke,

E-mail: drrajshrikatke@gmail.com

Copyright: (C) the author(s), publisher and licensee Medip Academy. This is an open-access article distributed under the terms of the Creative Commons Attribution Non-Commercial License, which permits unrestricted non-commercial use, distribution, and reproduction in any medium, provided the original work is properly cited.

\begin{abstract}
ITP occurs in approximately 2 of 1000 pregnant women. ITP may develop at any time during pregnancy, but is often initially recognized in the first trimester and is the most common cause of isolated thrombocytopenia in this time period. A 33 year old, married since 6 years, G2p111 with 33 weeks gestation referred to our tertiary centre. She was a known case of ITP with splenectomy done. She had a 5 year old male child, delivered by LSCS. She was diagnosed as having ITP at the age of 12 years. HCV antibody was weakly positive. ANA was positive. Emergency LSCS was done in view of scar tenderness. Post op she developed epistaxis, bleeding gums and per vaginum. Patient received multiple FFP, platelet transfusions and responded to treatment with methylprednisolone. The diagnosis and management of ITP in pregnancy is similar to that in the non-pregnant adult patient, but the risks to the developing fetus must be taken into account when choosing treatment and the maintenance of a safe platelet count, rather than prolonged remission, is the goal. Mode of delivery must be guided by obstetrical indications.
\end{abstract}

Keywords: Idiopathic thrombocytopenic purpura, ITP with pregnancy

\section{INTRODUCTION}

Thrombocytopenia is a common finding in pregnancy. Establishing the diagnosis of immune thrombocytopenia (ITP) in a pregnant patient is similar to doing so in a nonpregnant patient, except that the evaluation must specifically rule out other disorders of pregnancy associated with low platelet counts that present different risks to the mother and fetus and may require alternate distinct therapy.

With proper management and monitoring, positive outcomes can be expected in the majority of patients. We report a successfully managed case of a known case of ITP with splenectomy done with HCV antibody positive with previous LSCS, the management of which was challenging.

\section{CASE REPORT}

Patient was a 33 year old, married since 6 years, G2p111 with 33 weeks gestation referred from a government hospital to our tertiary centre. She was a known case of ITP with splenectomy done. She had a 5 year old male child, delivered by LSCS done due to non-progress of labour. She was diagnosed as having ITP at the age of 12 years (1983) after she had hematuria, menorrhagia, epistaxis. Splenectomy was one in 1989. She was given multiple blood, platelet, FFP transfusions in the past. Pneumococcal vaccine was given in 1994. In 2009 she had right sided lymphadenopathy. Biopsy was suggestive of reactive lymphoid hyperplasia. She was allergic to septran. On admission vitals were stable. There was no pallor, cyanosis, clubbing. Respiratory and cardiologic systemic examination was unremarkable. On per 
abdomen examination uterus was 28-30 weeks size, relaxed. Per speculum examination - cervix, vagina healthy. On per vaginum examination os was closed, posterior. On admission her hemoglobin was 10.3, CBC was 19200 and platelet count was 141000. Coagulation profile was normal. Peripheral smear - hypochromasia, anisocytosis, Howell-Jolly bodies, giant platelets. HCV antibody was weakly positive. ANA was positive, Coombs factor, RA factor, anti-ds DNA was negative. USG obstetrics and abdomen had normal findings. Patient developed painful swelling over right mastoid region. USG s/o inflammatory origin on the swelling. Antibiotics were given. Patient went into spontaneous labour and emergency LSCS was done in view of scar tenderness. Patient was given 2pints of platelets and 4 pints of FFP introperatively. In post op period patient had high grade fever on $3^{\text {rd }}$ day of LSCS responded to Anti malarials. Afterward post op course was uneventful till $16^{\text {th }}$ post op day when patient started bleeding per vaginum. Her haemoglobin was $9 \mathrm{~g} \%$, platelets 138000 , coagulation profile normal. On $18^{\text {th }}$ post-operative day she had bleeding from gums, per vaginum and epistaxis. Platelet count was 20000. 20 pints platelets and 2 pint blood given. Patient was given inj. methyl prednisolone injectable followed by oral. Patients platelet count improved and patient became symptomatically better and responded to our treatment and was discharged with a healthy baby.

\section{DISCUSSION}

Pregnant women with ITP can be asymptomatic or may present with a history of easy bruisability, bleeding into the mucous membranes (epistaxis or gingival bleeding), or purpura ITP occurs in all races and is diagnosed more commonly in females than males (ratio 3:1) specially in women of child bearing age $\left(2^{\text {nd }}\right.$ and $3^{\text {rd }}$ decade of life) with an incidence of one to two in 1000 pregnancies. They may have a history of menorrhagia or menometrorrhagia prior to pregnancy, history of delivering a term newborn with thrombocytopenia, visceral or intracranial hemorrhage, or spontaneous or prolonged bleeding after venipuncture. ${ }^{4}$ Most women with ITP have normal findings on physical examination (splenomegaly is absent) and purpura may be present especially in the lower limb. ${ }^{1-8}$

ITP occurs in approximately 2 of 1000 pregnant women. ${ }^{9}$ ITP may develop at any time during pregnancy, but is often initially recognized in the first trimester and is the most common cause of isolated thrombocytopenia in this time period. In some cases, ITP presents for the first time during pregnancy, whereas preexisting cases of ITP may either worsen or remain quiescent. ${ }^{10,11}$ ITP in the first and second trimesters is generally treated when the patient is symptomatic with bleeding, platelet counts are in the $20-30000 / \mu \mathrm{L}$ range, or a planned procedure requires a higher platelet count. Therapy late in gestation is generally based on the risk of maternal hemorrhage at delivery. First-line therapy for ITP in pregnancy is similar to the management of acute ITP: corticosteroids $^{12}$ and IVIgs. ${ }^{13}$ ITP in the mother is not an indication for caesarean section, and the mode of delivery in a pregnant patient with ITP is based on obstetric indications. Most neonatal hemorrhage occurs at 24-48 hours and is not related to trauma at the time of delivery. $^{14,15}$

\section{CONCLUSION}

Other disorders that may be associated with thrombocytopenia must be considered and ruled out so that appropriate therapy can be instituted. The diagnosis and management of ITP in pregnancy is similar to that in the non-pregnant adult patient, but the risks to the developing fetus must be taken into account when choosing treatment and the maintenance of a safe platelet count, rather than prolonged remission, is the goal. Mode of delivery must be guided by obstetrical indications. A history of ITP or ITP in a previous pregnancy is not a contraindication to pregnancy, and the majority of patients deliver non-thrombocytopenic or only mildly thrombocytopenic infants.

\section{Funding: No funding sources \\ Conflict of interest: None declared \\ Ethical approval: Not required}

\section{REFERENCES}

1. Jamaes N. George, Muzahid A. Rizvi. Thrombocytopenia. In: Ernest Beutler, Marshall A. Lichtman, Barry S. Coller, Thonmas J Kipps, Uri Seligsohn, eds. Williams Haematology. 6th ed. New York: McGraw-Hill; 2001: 1514-1520.

2. Giles C, Inglis TCM. Thrombocytopenia and macrothrombocytosis in gestational hypertension. $\mathrm{Br}$ J Obstet Gynaecol. 1981;88:1115.

3. Carr JM, Kruskall MS, Kaye JA, Robinson SH. Efficacy of platelet transfusions in immune thrombocytopenia. Am J Med. 1986;80:1051.

4. Frank Firkin, Colin Chesterman, David Penington, Bryan Rush. The hemorrhagic disorder: capillary and platelet defects. In: Frank Firkin, Colin Chesterman, David Penington, Bryan Rush, eds. de Gruchy's Clinical Haematology in Medical Practice. 5th ed. UK: Blackwell Science; 1989: 377-385.

5. Robert N. Handin. Clotting disorders. In: Robert N. Handin, eds. Harrison Principle of Medicine. 13th ed. New York: McGraw-Hill; 1994: 1800.

6. George JN, EI-Harake MA, Raskob GE. Chronic idiopathic thrombocytopenic purpura. N Eng J Med. 1994;331:1207.

7. Lynnae Millar. Immune thrombocytopenia and pregnancy, 2014. Available at: http://emedicine.medscape.com/article/208697clinical. Accessed 5 June 2014.

8. Keith Edmonds. Disorders of platelets in pregnancy. In: Keith Edmonds, eds. Dewhurst's Textbook of 
Obstetrics and Gynaecology for Postgraduates. 6th ed. UK: Blackwell Science; 1999: 229-233.

9. Gill KK, Kelton JG. Management of idiopathic thrombocytopenic purpura in pregnancy. Semin Haematol. 2000;37(3):275-89.

10. Won YW, Moon W, Yun YS, Oh HS, Choi JH, Lee YY, et al. Clinical aspects of pregnancy and delivery in patients with chronic idiopathic thrombocytopenic purpura (ITP). Korean J Intern Med. 2005;20(2):12934.

11. Fujimura K, Harada Y, Fujimoto T, Kuramoto A, Ikeda Y, Akatsuka J, et al. Nationwide study of idiopathic thrombocytopenic purpura in pregnant women and the clinical influence on neonates. Int $\mathrm{J}$ Haematol. 2002;75(4):426-33.

12. Karpatkin S. Autoimmune thrombocytopenic purpura. Semin Haematol. 1985;22(4):260-88.
13. Besa EC, MacNab MW, Solan AJ, Lapes MJ, Marfatia U. High-dose intravenous $\mathrm{IgG}$ in the management of pregnancy in women with idiopathic thrombocytopenic purpura. Am J Haematol. 1985;18(4):373-9.

14. Kaplan C, Daffos F, Forestier F, Tertian G, Catherine $\mathrm{N}$, Pons JC, et al. Fetal platelet counts in thrombocytopenic pregnancy. Lancet. 1990;336(8727):979-82.

15. Bussel JB, Druzin ML, Cines DB, Samuels P. Thrombocytopenia in pregnancy. Lancet. 1991;337(8735):251.

DOI: $10.5455 / 2320-1770 . i j \operatorname{rcog} 20141250$

Cite this article as: Katke RD. A rare and successfully managed case of idiopathic thrombocytopenic purpura (ITP) with previous caesarean with splenectomy with hepatitis C positive. Int J Reprod Contracept Obstet Gynecol 2014;3:1119-21. 